\title{
Comparison of Electrocardiography Markers and Speckle Tracking Echocardiography for Assessment of Left Ventricular Myocardial Scar Burden in Patients with Previous Myocardial Infarction
}

Running title: Scar Burden in Myocardial Infarction

Eirik Nestaas, $M D^{a, b}$, Jhih-Yuan Shih, $M D^{a, c}$, Marit K. Smedsrud, MD ${ }^{a}$, Ola Gjesdal, MDª Einar Hopp, $M D^{a, d}$, Kristina H. Haugaa, $M D^{a, b}$, Thor Edvardsen, $M D^{a, b}$

${ }^{a}$ Dept of Cardiology and Center for Cardiological Innovation, Oslo University Hospital, Rikshospitalet, Oslo, Norway

${ }^{\mathrm{b}}$ Institute for Clinical Medicine, Faculty of Medicine, University of Oslo, Oslo, Norway

${ }^{c}$ Division of Cardiology, Department of Internal Medicine, Chi-Mei Medical Center, Tainan, Taiwan

${ }^{d}$ Division of Radiology and Nuclear Medicine, Oslo University Hospital, Norway

Corresponding author: Thor Edvardsen

Phone: $\quad$ (+47) 23070000

Fax: $\quad$ (+47) 23071397

Email: thor.edvardsen@medisin.uio.no

Mail: $\quad$ Center for Cardiological Innovation

Dept. of Cardiology

Oslo University Hospital, Rikshospitalet

Sognsvannsveien 20

0372 Oslo

Norway

Date for resubmission: January 18, 2017 
Abstract

Myocardial scar burden is an important prognostic factor after myocardial infarction. This cohort study compared assessment of left ventricle scar burden between pathological Q-waves on electrocardiography (ECG), Selvester multi-parametric ECG scoring system for scar burden and global longitudinal strain (GLS) by speckle tracking echocardiography 6 months after myocardial infarction. The scar burden was defined by late gadolinium enhancement cardiac magnetic resonance as fraction of total left ventricle tissue. ECG measures were presence of pathological Q-waves and Selvester scores. GLS was the average of peak strain from 16 left ventricle segments. In 34 patients age $58 \pm 10$ years (mean \pm SD), the scar burden was $19(9,26) \%$ (median (quartiles)) and $79 \%$ had scar burden $>5 \%$. Patients with scar burden $>5 \%$ more frequently had pathological Q-waves (63\% vs. $14 \%$ ) and had worse Selvester scores $(5(3,7)$ vs. $0(0,1))$ and worse GLS $(-16.6 \pm 2.4 \%$ vs. $-19.9 \pm 1.1 \%)$. Pathological Q-waves, Selvester scores, ejection fraction and GLS related to scar burden in univariable analyses. Sensitivity and specificity for detecting scar burden $>5 \%$ was $63 \%$ and $86 \%$ (pathological Q-waves), 89\% and 86\% (Selvester score), 81\% and 86\% (ejection fraction), $89 \%$ and 86\% (GLS) and $96 \%$ and 71\% (combination of Q-waves, Selvester score and GLS). In conclusion, Selvester score and GLS related to scars 6 months after myocardial infarction, pathological Q-waves were only weakly associated with scar and GLS was associated with scar independently of ECG markers.

Keywords: Myocardial Infarction; Echocardiography; Electrocardiography; Magnetic Resonance Imaging 
Myocardial scar burden is an important prognostic factor after acute myocardial infarction. ${ }^{1}$ Late gadolinium enhancement cardiac magnetic resonance (LGE-CMR) is the reference method for quantification of scars following myocardial infarction. ${ }^{2,3}$ As LGE-CMR is costly, not available everywhere and has limitations or contraindications in several patient groups, bedside tools such as electrocardiography (ECG) and echocardiography are the most important first line methods for evaluation of infarct size in patients with prior myocardial infarction. Guidelines appreciate Q-waves on ECG as pathognomonic of prior myocardial infarction in patients with ischemic heart disease, ${ }^{4}$ and Q-waves relate to infarct size. ${ }^{5}$ The Selvester multi-parametric ECG scoring system combines the extent and morphology of Q-waves with other ECG indices to calculate scar burden. ${ }^{6}$ Longitudinal strain by 2-dimensional speckle tracking echocardiography is associated with the scar burden on LGE-

$\mathrm{CMR}^{7}$ No study has yet compared Q-waves, Selvester scores and longitudinal strain for quantification of scar burden after the acute phase of myocardial infarction. In this study, we related ECG indices and longitudinal strain to myocardial scar burden 6 months after acute myocardial infarction and used LGE-CMR as reference. We hypothesized that ECG indices and longitudinal strain relate to left ventricle scar burden.

\section{Methods}

The study population consisted of patients $\geq 18$ years with a history of acute myocardial infarction confirmed by ECG and elevated troponin I or troponin $\mathrm{T}>99$ percentile, recruited in a single tertiary coronary care center. We collected peak Tropinin I during the first days of the acute myocardial infarction and standard 12-lead ECG, 2-dimensional transthoracic echocardiography and LGE-CMR 6 months later. We excluded patients who (1) had incomplete datasets (ECG, echocardiography, and LGE-CMR 6 months after myocardial infarction); (2) had an ECG abnormality that interfered with the interpretation of Q-waves or Selvester score (left or right bundle branch block, left or right ventricular hypertrophy, left anterior or posterior fascicular block, or WolffParkinson-White syndrome); (3) had atrial fibrillation; or (4) had significant valvular heart disease. 
The Regional Committee for Medical Research (REK South, Oslo, Norway) approved the study. All subjects gave written informed consent.

We defined pathological Q-waves according to the third universal definition of myocardial infarction. ${ }^{4}$ A pathological Q-wave was (1) any Q-wave in leads V2-V3 $\geq 0.02$ sec or QS complex in leads V2 and V3; (2) Q-wave $\geq 0.03 \mathrm{sec}$ and $\geq 0.1 \mathrm{mV}$ deep or QS complex in leads I, II, aVL, aVF or V4V6 in any 2 leads of a contiguous lead grouping (I, aVL; V1-V6; II, III, aVF); (3) R-wave $\geq 0.04$ sec in V1$\mathrm{V} 2$ and $\mathrm{R} / \mathrm{S} \geq 1$ with a concordant positive T wave in absence of conduction defect.

The Selvester scoring system uses Q-, R-, and S- wave amplitudes, Q- and R-wave durations, and R/Q and R/S ratios to calculate scar burden. ${ }^{6}$ An ECG can obtain a maximum score of 32 points. Each point corresponds to approximately $3 \%$ scar burden in the left ventricle in autopsy specimen. ${ }^{6}$ We calculated the 32-point Selvester score for each ECG. ${ }^{6}$

All patients had echocardiography 6 months after the acute myocardial infarction using Vivid 7 and Vivid E9 systems (GE Healthcare, Horten, Norway). Using commercial software (EchoPAC PC), we calculated ejection fraction by Simpson's biplane method and longitudinal strains by 2dimensional speckle tracking echocardiography of the left ventricle from apical 4-chamber, 2chamber and long-axis views. After manually marking the endocardial border and the myocardial thickness, the analysis software performed automatic tracking and estimation of deformation in 6 segments from each view. We converted the measurements from these 18 segments into the standard 16-segment model of the left ventricle ${ }^{8}$ and assessed the global longitudinal strain (GLS) as the average of the peak negative strains for each of the 16 segments. All images used for 2dimensional speckle tracking echocardiography analysis had frame rate $\geq 50 \mathrm{~s}^{-1}$.

LGE-CMR was performed immediately after echocardiography by a 1.5-Tesla magnetic resonance imaging scanner (Magnetom Sonata, Siemens, Erlangen, Germany). Multiple short-axis slices covering the entire left ventricle were acquired 10-20 min after intravenous injection of 0.2 
$\mathrm{mmol} / \mathrm{kg}$ gadopentetate dimeglumine (Magnevist, Schering, Berlin, Germany). To quantify the scar burden of the left ventricle, we marked the total myocardial area and area of infarcted myocardium manually on each short-axis image (PACS, Sectra, Sweden) and summed up total myocardial and scar volumes. ${ }^{9}$ The scar burden was defined as the infarct tissue as $\%$ of total myocardial tissue, estimated as the fraction between the areas.

We present data as mean \pm standard deviation, median (quartiles) or dichotomously as appropriate and used $95 \%$ confidence intervals and 2 -sided $5 \% \mathrm{p}$-values for statistical tests. We compared groups by Fisher's exact test, Independent-samples Mann-Whitney U Test and Student's Ttest and used linear regression analyses to assess the impact from pathological Q-wave, Selvester score, ejection fraction and GLS on scar burden. We included constants in the linear regression analyses but performed a separate univariable regression analysis for the Selvester score without the constant to test the scar quantification capability of the Selvester score. ${ }^{6}$ We used the receiver operating characteristics curves to define optimal sensitivity, specificity, accuracy and for defining cut offs values for Selvester score, ejection fraction and GLS in logistic regression analyses. ${ }^{10}$ To avoid correlated independent variables in the multivariable analyses we did not include both ECG indices in the same models, because Q-wave is part of the Selvester score. In the combined analyses of ECG criteria and GLS for detecting scars $>5 \%$ and $>20 \%$, the tests were regarded positive if 1 or more of the dichotomous variables indicated disease. We compared sensitivities of ECG criteria vs. of GLS and ECG criteria by pairwise McNemar chi square tests for scar burden $>5 \%$ and $>20 \%$ thresholds and specificities by pairwise tests in patients with scars burden below the thresholds. ${ }^{11}$ We compared Rvalues between linear regression models by Fisher r-to-z transformation and assessed confidence intervals for sensitivities, specificities and accuracies by the efficient-score method. ${ }^{12}$

\section{Results}

Table 1 shows the patient characteristics stratified by $5 \%$ scar burden. All patients received beta-blockers at the time for examination. In the total material, the scar burden by LGE-CMR was 19 
$(9,26) \%$. The median Selvester ECG score was $4(1,6)$, and average GLS was $-17.2 \pm 2.6 \%$. Peak Troponin I during acute phase of infarction correlated significantly with scar burden ( $r=0.70$, $p<0.001)$. Age and gender did not differ between those with scar $>5 \%$ and $<5 \%$. Selvester score was higher and pathological Q-waves more frequent in those with scar $>5 \%$. The cardiac volumes did not differ between scar burden $>5 \%$ and $<5 \%$, but the ejection fraction and GLS were worse in those with scar burden $>5 \%$. Figure 1 shows ECG, LGE-CMR and strain analysis from a study patient.

Table 2 shows the linear relations between scars and pathological Q-wave, Selvester score, ejection fraction and GLS. All indices related significantly to scar burden in the univariable analyses. There were no significant differences in the models between any of the linear univariable and multivariable analyses. Ejection fraction correlated strongly with $G L S(r=0.72, p<0.001)$ and was therefore omitted from the multivariable analyses due to collinearity. Each point of Selvester score was associated with $3.9(3.1,4.7) \%$ higher scar burden in the analysis without a constant $(p<0.001)$. The optimal value for detecting scars $>5 \%$ by receiver operating characteristic curve analyses were $55 \%$ for ejection fraction, 1.5 points for the Selvester score and $-19.0 \%$ for GLS, with area under the curves of $0.82(0.66-0.97)$ for ejection fraction and $0.93(0.84-1.00)$ for Selvester score and for GLS. Table 3 shows sensitivity, specificity and accuracy for each index as markers of scars $>5 \%$ and odds ratios for the logistic regression analyses. All indices were markers of scars $>5 \%$ in the univariable analyses. Only GLS and Selvester score remained significant markers in the multivariable logistic analyses.

The scar burden was $>20 \%$ in 17 (50\%) of patients. As expected, the optimal cut off values were worse for $20 \%$ than for $5 \%$ scar burden ( 5 points for Selvester score and $-15.1 \%$ for GLS). Pathological Q-waves (13/17 vs. 5/17, p=0.015) and Selvester score $>$ the optimal cut off value $(11 / 17$ vs. $4 / 17, p=0.037$ ) were more frequent at high scar burden. The sensitivities, specificities and accuracies for $20 \%$ scar burden were $76(50,92) \%, 71(44,89) \%$ and $74(55,86) \%$ for pathological Q-waves and $65(39,85) \%, 76(50,92) \%$ and $71(52,84) \%$ for Selvester score. Table 4 shows the 
sensitivities, specificities and accuracies for tests for scars $>5 \%$ and $>20 \%$ solely by ECG criteria (pathological Q-wave and/or Selvester score) and by ECG criteria in combination with GLS criteria. Both for $5 \%$ and $20 \%$ scar burden, the combination of ECG and GLS criteria detected all except 1 patient with scars > the thresholds levels, with $2(29 \%)$ and $10(59 \%)$ false positive cases respectively. None of the differences in sensitivities or specificities between test by ECG indices vs. by combination of ECG and GLS indices were statistically significant.

\section{Discussion}

The present study is the first to compare Q-wave, Selvester score and deformation indices as markers of scar burden by LGE-CMR 6 months after acute myocardial infarction. Pathological Qwaves, Selvester score and GLS related significantly to scar burden and were markers of scar burden $>5 \%$ as individual indices. The Selvester score was a stronger marker than pathological Q-waves. The combination of ECG and GLS criteria had excellent sensitivities for detecting scar burden $>5 \%$ and $>20 \%$. This advocates the use of GLS in the follow-up of patients after myocardial infarction.

Detecting small amounts of scars is important because the prognosis for patients with silent scars is similar to those with known scars. ${ }^{13}$ Cardiac volumes were similar in hearts with and without scar while ejection fraction was associated with scars. Troponin I correlated significantly with scar burden size, in line with previous studies. ${ }^{14}$

The accuracy of pathological Q-wave as a marker of scars will depend on the desired threshold for scar burden and the definition of pathological Q-wave. ${ }^{5,15-17}$ Similar to other studies, ${ }^{5}$ we found higher scar burden in hearts with pathological Q-waves and that pathological Q-wave was a significant marker of scar burden $>5 \%$ and $>20 \%$. As demonstrated in our study, Q-waves have some shortcomings as a marker of prior myocardial infarction. ${ }^{4,5,16}$ Pathological Q-waves are associated with transmurality of scars ${ }^{18}$ but the presence of pathological Q-waves is more dependent on scar burden than transmurality. ${ }^{15}$ Pathological Q-waves can be absent in small infarctions ${ }^{15-17}$ and in 
transmural scars, ${ }^{5}$ and can be present in non-transmural scars ${ }^{19}$ and also in hearts with no scars on LGE-CMR. ${ }^{5}$ Due to this inconsistency, it has been suggested that the distinction between Q-infarction and non-Q-infraction is not clinically relevant and that the myocardial infarction should be judged on anatomical and functional considerations. ${ }^{20}$ Our results showed that using Q-waves as the only diagnostic criterion would miss $37 \%$ of all patients with scar burden $>5 \%$ and confirmed that pathological Q-waves can be present in patients with low scar burden. These considerations are increasingly more relevant since the majority of patients in the Western communities receive revascularization therapy, ${ }^{21}$ resulting in smaller infarcts as compared to the pre-reperfusion era. ${ }^{16,22,23}$

The Selvester scoring system uses Q-waves in combination with other ECG characteristics to quantify scars. ${ }^{6,24}$ Studies have shown analysis of Selvester score to be feasible and reproducible. ${ }^{22}$ Quantification of scar burden by Selvester score compared to MRI has shown small systematic differences but wide range in limits of agreement (within the range of $\pm 20 \%$ scar burden). ${ }^{22}$ Some have speculated that the relationship between Selvester score and scar burden is different after introduction of reperfusion therapies, because the scarred area has less distinct borders towards viable myocardium. ${ }^{25}$ The increase in scar burden per point Selvester score in our study was close to the findings in an in-vivo study ${ }^{26}$ and an autopsy study. ${ }^{6}$ The optimal Selvester score criterion value from the receiver operator characteristics curve was 1.5 points for scar burden $>5 \%$ and 5.0 points for scar burden $>20 \%$ in our study, in line with studies showing that the increase in scar burden per Selvester score point may be non-linear and lower in the era of reperfusion therapy. ${ }^{23}$

Longitudinal strain relates to scar burden., ${ }^{7,27}$ We are, however, not aware of previous studies exploring GLS as a marker for LV scar burden as low as down to 5\%. Compared to the sensitivity of $89 \%$ and specificity of $86 \%$ for detection of scar burden $>5 \%$ by GLS in our study, others have found much lower sensitivity and specificity for detecting infarct of any size by wall motion score by echocardiography. ${ }^{30}$ 
Opposed to studies of GLS and Selvester score in the acute phase of myocardial infarction, ${ }^{28}$ the Selvester score in our study related significantly to scar burden in the analyses together with GLS. The combination of ECG criteria and GLS identified patients with scar burden $>5 \%$ and $>20 \%$ with only 1 false-negative test at each threshold. There were few extra false-positive tests, especially for identification of small scars. The lack of significant differences between the sensitivities and specificities might be due to the relatively low number of patients. Our findings suggest the combination of ECG and GLS as a feasible test for identification of patients with scars following myocardial infarction in clinical practice.

Our study is a relatively small observational study and there is therefore a need for larger studies including patients with a broader range of ejection fractions to confirm our findings. We used a standard definition of pathological Q-waves. ${ }^{4}$ Using another definition could have altered the results although studies have shown small differences in presence of pathological Q-waves in infarcted patients depending on definitions. ${ }^{5}$ We used presence of pathological Q-waves dichotomously and the clinical feasibility of pathological Q-wave for scar quantification was therefore limited. Because we used the standard Selvester scoring system, we did not include patients with ECG abnormalities that interfered with the interpretation of Q-waves or Selvester score. Future studies should explore the relation between regional ECG findings, regional strain and regional localization of myocardial scar.

Funding: The Center for Cardiological Innovation funded by the Research Council of Norway supported the study. The sponsors were not involved in study design, in the collection, analysis and interpretation of data, in the writing of the report, or in the decision to submit the article for publication.

Conflicts of interest: None. 
1. Burns RJ, Gibbons RJ, Yi Q, Roberts RS, Miller TD, Schaer GL, Anderson JL, Yusuf S, Investigators CS. The relationships of left ventricular ejection fraction, end-systolic volume index and infarct size to sixmonth mortality after hospital discharge following myocardial infarction treated by thrombolysis. J Am Coll Cardiol 2002;39:30-36.

2. Kim RJ, Fieno DS, Parrish TB, Harris K, Chen EL, Simonetti O, Bundy J, Finn JP, Klocke FJ, Judd RM. Relationship of MRI delayed contrast enhancement to irreversible injury, infarct age, and contractile function. Circulation 1999;100:1992-2002.

3. Bainey KR, Patel MR, Armstrong PW. Evaluation of Cardiac Magnetic Resonance as a Surrogate in ST-Segment Elevation Myocardial Infarction. Am J Cardiol 2015;115:1607-1614.

4. Thygesen K, Alpert JS, Jaffe AS, Simoons ML, Chaitman BR, White HD, Writing Group on the Joint ESCAAHAWHFTFftUDoMI, Thygesen K, Alpert JS, White HD, Jaffe AS, Katus HA, Apple FS, Lindahl B, Morrow DA, Chaitman BA, Clemmensen PM, Johanson P, Hod H, Underwood R, Bax JJ, Bonow RO, Pinto F, Gibbons RJ, Fox KA, Atar D, Newby LK, Galvani M, Hamm CW, Uretsky BF, Steg PG, Wijns W, Bassand JP, Menasche P, Ravkilde J, Ohman EM, Antman EM, Wallentin LC, Armstrong PW, Simoons ML, Januzzi JL, Nieminen MS, Gheorghiade M, Filippatos G, Luepker RV, Fortmann SP, Rosamond WD, Levy D, Wood D, Smith SC, Hu D, Lopez-Sendon JL, Robertson RM, Weaver D, Tendera M, Bove AA, Parkhomenko AN, Vasilieva EJ, Mendis S, Guidelines ESCCfP. Third universal definition of myocardial infarction. Eur Heart J 2012;33:2551-2567.

5. Nadour W, Doyle M, Williams RB, Rayarao G, Grant SB, Thompson DV, Yamrozik JA, Biederman RW. Does the presence of $Q$ waves on the EKG accurately predict prior myocardial infarction when compared to cardiac magnetic resonance using late gadolinium enhancement? A cross-population study of noninfarct vs infarct patients. Heart Rhythm 2014;11:2018-2026.

6. Selvester RH, Wagner GS, Hindman NB. The Selvester QRS scoring system for estimating myocardial infarct size. The development and application of the system. Arch Intern Med $1985 ; 145: 1877-1881$. 
7. Roes SD, Mollema SA, Lamb HJ, van der Wall EE, de Roos A, Bax JJ. Validation of echocardiographic two-dimensional speckle tracking longitudinal strain imaging for viability assessment in patients with chronic ischemic left ventricular dysfunction and comparison with contrast-enhanced magnetic resonance imaging. Am J Cardiol 2009;104:312-317.

8. Lang RM, Badano LP, Mor-Avi V, Afilalo J, Armstrong A, Ernande L, Flachskampf FA, Foster E, Goldstein SA, Kuznetsova T, Lancellotti P, Muraru D, Picard MH, Rietzschel ER, Rudski L, Spencer KT, Tsang W, Voigt JU. Recommendations for cardiac chamber quantification by echocardiography in adults: an update from the American Society of Echocardiography and the European Association of Cardiovascular Imaging. Eur Heart J Cardiovasc Imaging 2015;16:233-270.

9. Cerqueira MD, Weissman NJ, Dilsizian V, Jacobs AK, Kaul S, Laskey WK, Pennell DJ, Rumberger JA, Ryan T, Verani MS. Standardized myocardial segmentation and nomenclature for tomographic imaging of the heart: a statement for healthcare professionals from the Cardiac Imaging Committee of the Council on Clinical Cardiology of the American Heart Association. Circulation 2002;105:539542.

10. Greiner M, Pfeiffer D, Smith RD. Principles and practical application of the receiver-operating characteristic analysis for diagnostic tests. Prev Vet Med 2000;45:23-41.

11. Trajman A, Luiz RR. McNemar chi2 test revisited: comparing sensitivity and specificity of diagnostic examinations. Scand J Clin Lab Invest 2008;68:77-80.

12. Newcombe RG. Two-sided confidence intervals for the single proportion: comparison of seven methods. Stat Med 1998;17:857-872.

13. Jaarsma C, Bekkers SC, Haidari Z, Smulders MW, Nelemans PJ, Gorgels AP, Crijns HJ, Wildberger JE, Schalla S. Comparison of different electrocardiographic scoring systems for detection of any previous myocardial infarction as assessed with cardiovascular magnetic resonance imaging. Am J Cardiol 2013;112:1069-1074. 
14. Hallen J, Buser P, Schwitter J, Petzelbauer P, Geudelin B, Fagerland MW, Jaffe AS, Atar D. Relation of cardiac troponin I measurements at 24 and 48 hours to magnetic resonance-determined infarct size in patients with ST-elevation myocardial infarction. Am J Cardiol 2009;104:1472-1477.

15. Moon JC, De Arenaza DP, Elkington AG, Taneja AK, John AS, Wang D, Janardhanan R, Senior R, Lahiri A, Poole-Wilson PA, Pennell DJ. The pathologic basis of Q-wave and non-Q-wave myocardial infarction: a cardiovascular magnetic resonance study. J Am Coll Cardiol 2004;44:554-560.

16. Kochav JD, Okin PM, Wilson S, Afroz A, Renilla A, Weinsaft JW. Usefulness of Q-wave area for threshold-based stratification of global left ventricular myocardial infarct size. Am J Cardiol 2013;112:174-180.

17. Kaandorp TA, Bax JJ, Lamb HJ, Viergever EP, Boersma E, Poldermans $D$, van der Wall EE, de Roos A. Which parameters on magnetic resonance imaging determine $Q$ waves on the electrocardiogram? Am J Cardiol 2005;95:925-929.

18. Prinzmetal M, Shaw CM, Jr., Maxwell MH, Flamm EJ, Goldman A, Kimura N, Rakita L, Borduas JL, Rothman S, Kennamer R. Studies on the mechanism of ventricular activity. VI. The depolarization complex in pure subendocardial infarction; role of the subendocardial region in the normal electrocardiogram. Am J Med 1954;16:469-489.

19. Pipberger H, Schwartz L, Massumi RA, Weiner SM, Prinzmetal M. Studies on the mechanism of ventricular activity. XXI. The origin of the depolarization complex, with clinical applications. Am Heart J 1957;54:511-530.

20. Phibbs B, Marcus F, Marriott HJ, Moss A, Spodick DH. Q-wave versus non-Q wave myocardial infarction: a meaningless distinction. J Am Coll Cardiol 1999;33:576-582.

21. Siontis KC, Barsness GW, Lennon RJ, Holmen JL, Wright RS, Bell MR, Gersh BJ. Pharmacoinvasive and Primary Percutaneous Coronary Intervention Strategies in ST-Elevation Myocardial Infarction (from the Mayo Clinic STEMI Network). Am J Cardiol 2016;117:1904-1910.

22. Strauss DG, Selvester RH, Lima JA, Arheden H, Miller JM, Gerstenblith G, Marban E, Weiss RG, Tomaselli GF, Wagner GS, Wu KC. ECG quantification of myocardial scar in cardiomyopathy patients 
with or without conduction defects: correlation with cardiac magnetic resonance and arrhythmogenesis. Circ Arrhythm Electrophysiol 2008;1:327-336.

23. Carlsen EA, Bang LE, Ahtarovski KA, Engstrom T, Kober L, Kelbaek H, Vejlstrup N, Jorgensen E, Helqvist S, Saunamaki K, Clemmensen P, Holmvang L, Wagner GS, Lonborg J. Comparison of Selvester QRS score with magnetic resonance imaging measured infarct size in patients with ST elevation myocardial infarction. J Electrocardiol 2012;45:414-419.

24. Selvester RH, Wagner JO, Rubin HB. Quantitation of Myocardial Infarct Size and Location by Electrocardiogram and Vectorcardiogram. In: Snellen HA, Hemker HC, Hugenholtz PG, Bemmel JH, eds. Quantitation in Cardiology. Dordrecht: Springer Netherlands, 1971:31-44.

25. Rovers WC, van Boreen MC, Robinson M, Martin TN, Maynard C, Wagner GS, Gorgels AP. Comparison of the correlation of the Selvester QRS scoring system with cardiac contrast-enhanced magnetic resonance imaging-measured acute myocardial infarct size in patients with and without thrombolytic therapy. J Electrocardiol 2009;42:139-144.

26. Knippenberg SA, Wagner GS, Ubachs JF, Gorgels A, Hedstrom E, Arheden H, Engblom H. Consideration of the impact of reperfusion therapy on the quantitative relationship between the Selvester QRS score and infarct size by cardiac MRI. Ann Noninvasive Electrocardiol 2010;15:238-244. 27. Gjesdal O, Hopp E, Vartdal T, Lunde K, Helle-Valle T, Aakhus S, Smith HJ, Ihlen H, Edvardsen T. Global longitudinal strain measured by two-dimensional speckle tracking echocardiography is closely related to myocardial infarct size in chronic ischaemic heart disease. Clin Sci (Lond) 2007;113:287296.

28. Vartdal T, Brunvand $H$, Pettersen $E$, Smith HJ, Lyseggen $E$, Helle-Valle $T$, Skulstad $H$, Ihlen $H$, Edvardsen T. Early prediction of infarct size by strain Doppler echocardiography after coronary reperfusion. J Am Coll Cardiol 2007;49:1715-1721.

29. Haugaa KH, Grenne BL, Eek CH, Ersboll M, Valeur N, Svendsen JH, Florian A, Sjoli B, Brunvand H, Kober L, Voigt JU, Desmet W, Smiseth OA, Edvardsen T. Strain echocardiography improves risk 
prediction of ventricular arrhythmias after myocardial infarction. JACC Cardiovasc Imaging 2013;6:841-850.

30. Jaarsma C, Schalla S, Cheriex EC, Smulders MW, van Dongen I, Nelemans PJ, Gorgels AP, Wildberger JE, Crijns HJ, Bekkers SC. Incremental value of cardiovascular magnetic resonance over echocardiography in the detection of acute and chronic myocardial infarction. J Cardiovasc Magn Reson 2013;15:5. 
Figure captions:

Figure 1. Electrocardiography (A), late enhancement magnetic resonance 4-chamber image (B) and segmental 4-chamber speckle tracking 2D-strain analysis (C) from a study patient. The white arrows in panel $B$ and $C$ denote findings from a scar in the apical lateral region. The apical (magenta) and mid (dark blue) inferior segmental strain curves in panel C show reduced systolic function compared to the other segments. The dotted white curve is the strain for the entire sample area. X-axis: Time. Yaxis: Longitudinal strain (\%). AVC: Aortic valve closure. 
Table 1. Patient characteristics stratified by scar burden $<5 \%(n=7)$ and $>5 \%(n=27)$ and $p$-value for difference between groups. Peak Troponin I is the maximal value during the acute phase of myocardial infarction.

\begin{tabular}{lccc}
\hline Parameter & $\begin{array}{c}\text { Scar burden }<5 \% \\
(\mathrm{n}=7)\end{array}$ & $\begin{array}{c}\text { Scar burden }>5 \% \\
(\mathrm{n}=27)\end{array}$ & p-value \\
& & & \\
\hline Age (years) & $59 \pm 14$ & $57 \pm 9$ & 0.684 \\
Female & $2(29 \%)$ & $9(33 \%)$ & 1.000 \\
Left ventricle end-diastolic volume (ml) & $150(104,184)$ & $135(120,164)$ & 0.803 \\
Left ventricle end-systolic volume (ml) & $50(30,62)$ & $58(40,78)$ & 0.177 \\
Ejection fraction (\%) & $60 \pm 7$ & $49 \pm 10$ & 0.013 \\
Q-wave on electrocardiography & $1(14 \%)$ & $17(63 \%)$ & 0.035 \\
Selvester score & $0(0,1)$ & $5(3,7)$ & $<0.001$ \\
Global longitudinal strain (\%) & $-19.9 \pm 1.1$ & $-16.6 \pm 2.4$ & 0.001 \\
Peak Troponin I (microgram/l) & $7(2,11)$ & $48(24,96)$ & 0.001 \\
Percentage of scar on late gadolinium & $0.6(0.0,4.0)$ & $21.9(16.2,28.6)$ & $<0.001$ \\
enhancement cardiac magnetic resonance (\%) & & & \\
\hline
\end{tabular}


Table 2. Relation between scar burden and pathological Q-waves, Selvester score and global longitudinal strain in linear univariable and multivariable analyses. See text for details.

\begin{tabular}{|c|c|c|c|}
\hline & Beta & p-value & R-square (adjusted) \\
\hline \multicolumn{4}{|l|}{ Univariable analyses } \\
\hline Q-wave (scar-\% increase if present) & $11.6(4.4,18.8)$ & 0.003 & 0.21 \\
\hline Selvester score (scar-\% increase per point) & $2.4(1.2,3.6)$ & $<0.001$ & 0.31 \\
\hline Ejection fraction (scar-\% increase per ejection fraction-\%) & $-0.69(-1.03,-0.35)$ & $<0.001$ & 0.31 \\
\hline Longitudinal strain (scar-\% increase per strain-\%) & $3.2(2.0,4.4)$ & $<0.001$ & 0.45 \\
\hline \multicolumn{4}{|l|}{ Multivariable analysis of Q-wave and global longitudinal strain } \\
\hline Q-wave (scar-\% increase if present) & $8.1(3.6,12.6)$ & 0.008 & \\
\hline Longitudinal strain (scar-\% increase per strain-\%) & $2.8(1.7,3.9)$ & $<0.001$ & 0.55 \\
\hline \multicolumn{4}{|c|}{ Multivariable analysis of Selvester score and global longitudinal strain } \\
\hline Selvester score (scar-\% increase per point) & $1.5(0.4,2.5)$ & 0.010 & \\
\hline Longitudinal strain (scar-\% increase per strain-\%) & $2.5(1.4,3.7))$ & $<0.001$ & 0.54 \\
\hline
\end{tabular}

Beta are values with $95 \%$ confidence intervals. 
Table 3. Sensitivity, specificity, accuracy and logistic regression analyses for presence of scar burden $>5 \%$ by pathological Q-waves, Selvester score, ejection fraction and global longitudinal strain. See text for details.

\begin{tabular}{|c|c|c|c|c|c|c|}
\hline & \multirow[b]{2}{*}{ Sensitivity (\%) } & \multirow[b]{2}{*}{ Specificity (\%) } & \multirow[b]{2}{*}{ Accuracy (\%) } & \multicolumn{3}{|c|}{ Logistic regression } \\
\hline & & & & Log odds ratio & $p$-value & Cox\&Snell R-square \\
\hline \multicolumn{7}{|c|}{ Univariable analyses } \\
\hline Q-wave & $63(42,80)$ & $86(42,99)$ & $68(49,82)$ & $2.3(0.1,4.6)$ & 0.044 & 0.15 \\
\hline Selvester score & $89(70,97)$ & $86(42,99)$ & $88(72,96)$ & $3.9(1.4,6.3)$ & 0.002 & 0.35 \\
\hline Ejection fraction & $81(61,93)$ & $86(42,99)$ & $82(65,93)$ & $3.3(0.9,5.6)$ & 0.006 & 0.28 \\
\hline \multicolumn{7}{|l|}{$\begin{array}{l}\text { longitudinal } \\
\text { strain }\end{array}$} \\
\hline \multicolumn{7}{|c|}{ Multivariable analysis of Q-wave and global longitudinal strain } \\
\hline Q-wave & & & & $2.6(-0.4,5.6)$ & 0.085 & \\
\hline Global longitudin & & & & $4.1(1.3,6.9)$ & 0.005 & 0.42 \\
\hline \multicolumn{7}{|c|}{ Multivariable analysis of Selvester score and global longitudinal strain } \\
\hline Selvester score & & & & $3.2(0.3,6.0)$ & 0.029 & \\
\hline Global longitudin & & & & $3.2(0.3,6.0)$ & 0.029 & 0.45 \\
\hline
\end{tabular}

Log odds ratios are values with $95 \%$ confidence intervals. Specificity, sensitivity and accuracy are $\%$ with $95 \%$ confidence intervals. 
Table 4. Sensitivities, specificities and accuracies of tests for scar burden $>5 \%$ and $>20 \%$ solely by electrocardiographic criteria (pathological Q-wave and/or Selvester score) and by electrocardiographic criteria in combination with global longitudinal strain. See text for details.

\begin{tabular}{|c|c|c|c|c|}
\hline Scar threshold & Diagnostics variables & Sensitivity & Specificity & Accuracy \\
\hline \multicolumn{5}{|l|}{ Scar $>5 \%$} \\
\hline & Electrocardiography & $89(70,97)$ & $86(42,99)$ & $88(72,96)$ \\
\hline & $\begin{array}{l}\text { Electrocardiography and } \\
\text { global longitudinal strain }\end{array}$ & $96(79,100)$ & $71(30,95)$ & $91(75,98)$ \\
\hline \multicolumn{5}{|l|}{ Scar $>\mathbf{2 0} \%$} \\
\hline & Electrocardiography & $76(50,92)$ & $59(33,81)$ & $68(49,82)$ \\
\hline & $\begin{array}{l}\text { Electrocardiography and } \\
\text { global longitudinal strain }\end{array}$ & $94(69,100)$ & $41(19,67)$ & $68(49,82)$ \\
\hline
\end{tabular}

Sensitivity, specificity and accuracy are $\%$ with $95 \%$ confidence intervals. 
Click here to download high resolution image

A

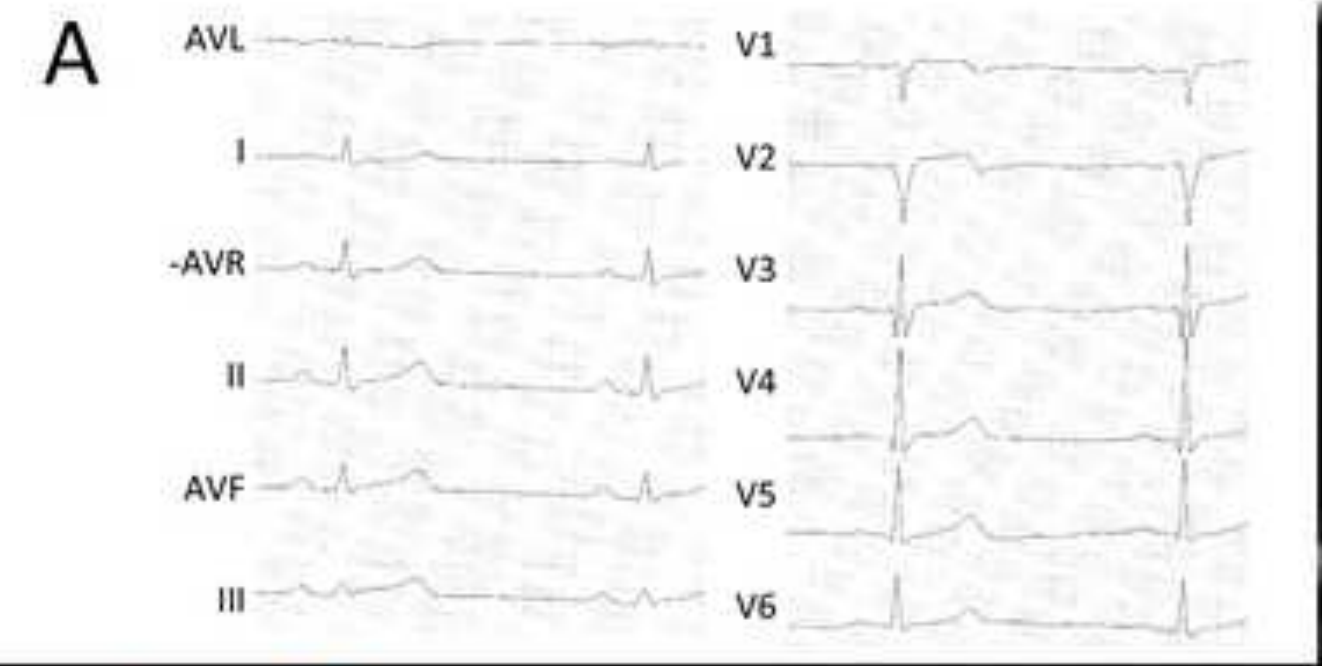

B
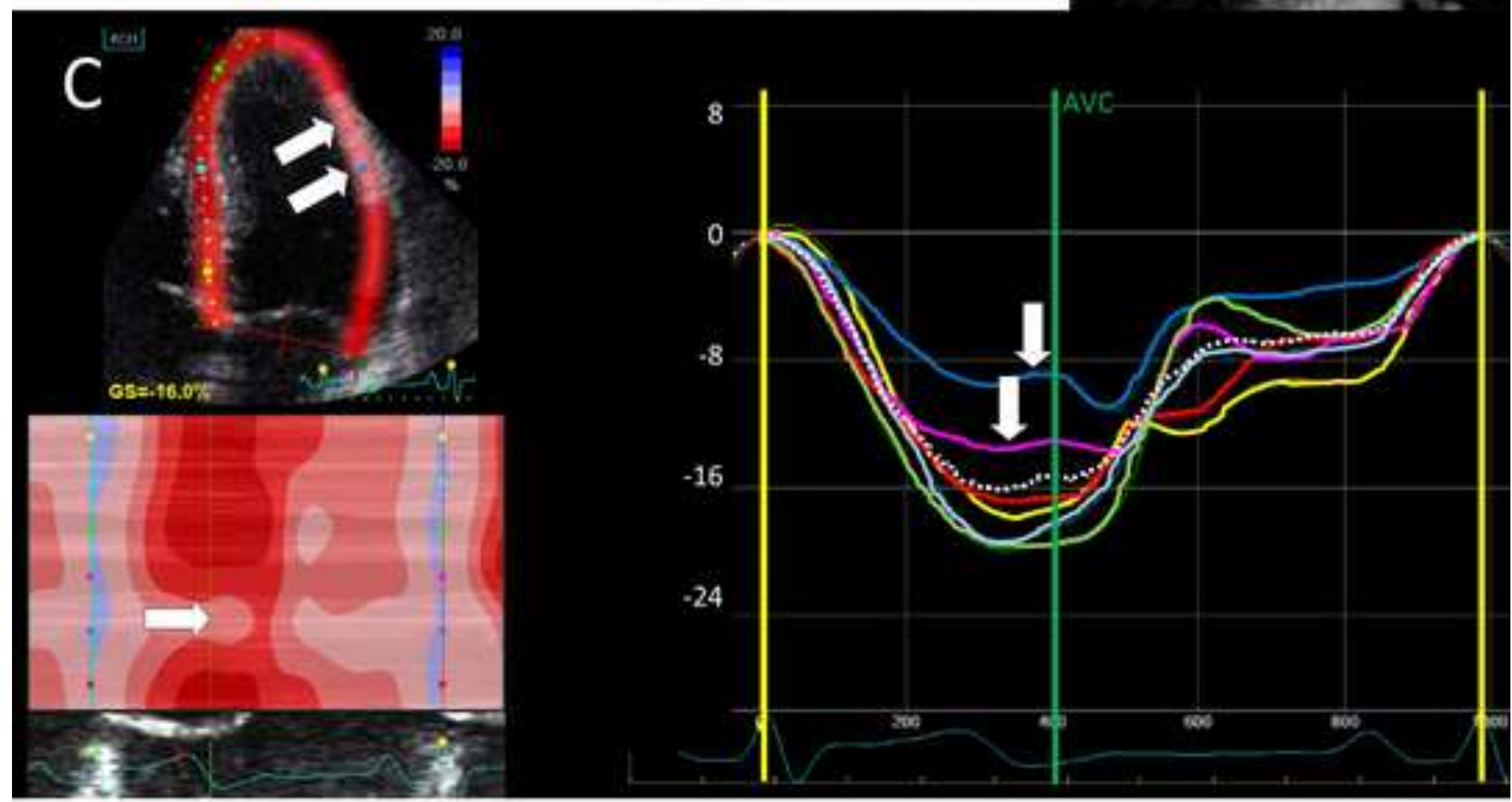

Note: This figure should be in color in print and on the web 